\title{
Discussion on the Earthquake Insurance in China Drawing on the International Experience
}

\author{
Long Wang, Aiwen Liu, Qiumei He, Na Yang, Sen Qiao \\ Institute of Geophysics, China Earthquake Administration, Beijing 100081, China
}

借鉴国际经验探讨我国地震保险事业的发展

王龙, 刘爱文, 贺秋梅, 杨娜, 乔森

中国地震局地球物理研究所, 北京 100081 , 中国

\begin{abstract}
Earthquake Insurance is attracting more and more attention in China with the development of economy and society, specially after 2008 Wenchuan Ms 8.0 earthquake. Earthquake Insurance is more difficult to popularize than other disaster's insurance because it is a sudden and strong destructive catastrophe with serious secondary disaster. The development of Earthquake Insurance in China is reviewed and the successful experiences of popularizing Earthquake Insurance are summed up through the comprehensive comparison with the 3 typical earthquake insurance systems. The relationship between direct economic loss and earthquake magnitude is studied with 122 earthquakes from 2006 to 2017. Finally, corresponding suggestions and countermeasures are put forward in view of the difficulties and problems faced by China's earthquake insurance.
\end{abstract}

Keywords: Earthquake Insurance; Direct economic loss; Catastrophe compensation mechanism

\section{摘要}

随着我国经济社会发展, 地震保险日益受到关 注, 特别是汶川地震之后。由于地震灾害具有突发 性高、损失巨大、次生灾害严重等特点, 地震保险 相比其他灾种具有更大的实施难度。本文回顾了我 国地震保险发展历程, 通过比较国际上 3 个典型地 震保险制度, 总结了地震保险的特点与国际上成功 经验, 统计分析了 2006 年-2017 年 122 次地震震
级与直接经济损失之间关系。最后针对我国地震保 险面临的困难与问题提出了相应建议和对策。

关键词：地震保险；直接经济损失；巨灾补偿机制

\section{1. 引言}

地震保险是利用保险经济手段, 通过设立地震 保险基金等方式, 补偿因地震灾害造成的损失。某 种意义上, 地震保险是有效应对地震灾害损失、转 移地震灾害风险的市场经济手段。我国作为世界上 地震活动最为强烈的国家之一, 大部分省、自治区、 直辖市在历史上都发生过多次破坏性地震, 地震灾 害风险极高。随着我国市场经济飞速发展, 破坏性 地震的发生会对我国经济社会发展产生严重负面 影响, 这时发挥地震保险的作用愈加重要。刑同时, 随着我国全社会风险意识的不断提升, 㓞性城乡建 设等工作快速推进, 对于地震灾害风险保障需求更 加强烈。国外许多地震灾害严重的国家已经建立了 较为完善的地震保险制度, 在破坏性地震中发挥了 重要的作用。而我国的地震保险则还处于起步阶段, 震后救灾与恢复重建主要依赖中央政府。本文在分 析总结国外实施地震保险制度的基础上, 提出适合 我国国情的地震保险开展建议, 使地震保险成为我 国减轻地震灾害损失的重要手段。

\section{2. 国外开展地震保险的经验}

破坏性地震造成的经济损失巨大, 动轩数亿、 数十亿甚至数百亿美元, 发生的规律也不可预测, 保险公司运营的 “大数法则” 难以运用, 因此地震 保险的开展过程中面临着诸多困难。一些地震比较 活跃的发达国家，如日本、美国、新西兰、土耳其 等国家的地震保险业务运行良好, 已经建立了较为 
完善的地震保险制度。总结这些在推进地震保险工 作开展的过程中积累的宝贵经验, 所建立的保险制 度和运行机制对我国具有很高的借鉴意义。

目前国外的地震保险可以划分为三种比较典 型的模式: 政府主导-市场辅助型、政府-市场互相 合作型、市场主导-政府辅助型, 如表 1 所示 ${ }^{[2]}$ 。 每个国家的国情不同, 因此采取的地震保险制度、 机制也不同。

\begin{tabular}{|c|c|c|c|}
\hline 模式 & 模式概述 & 特点 & $\begin{array}{c}\text { 代表 } \\
\text { 性国 } \\
\text { 家 }\end{array}$ \\
\hline $\begin{array}{l}\text { 政府 } \\
\text { 主导 } \\
\text {-市 } \\
\text { 场辅 } \\
\text { 助型 }\end{array}$ & $\begin{array}{l}\text { 政府为主 } \\
\text { 导, 提供 } \\
\text { 财政和制 } \\
\text { 度保障, } \\
\text { 直接经营 } \\
\text { 地震保险 } \\
\text { 产品。 }\end{array}$ & $\begin{array}{l}\text { 基于政府的财政和制 } \\
\text { 度保障, 政府管理介 } \\
\text { 入度高, 可以有效应 } \\
\text { 对地震灾害风险的突 } \\
\text { 然性和严重性, 但是 } \\
\text { 缺乏发挥市场操作的 } \\
\text { 灵活性, 对财政及政 } \\
\text { 策依赖度大。 }\end{array}$ & $\begin{array}{c}\text { 新西 } \\
\text { 兰 }\end{array}$ \\
\hline $\begin{array}{l}\text { 政府 } \\
\text {-市 } \\
\text { 场互 } \\
\text { 相合 } \\
\text { 作型 }\end{array}$ & $\begin{array}{l}\text { 与市场操 } \\
\text { 作达成平 } \\
\text { 衡, 政府 } \\
\text { 间接介入 } \\
\text { 地震保险 } \\
\text { 市场。 }\end{array}$ & $\begin{array}{l}\text { 由保险市场提供并经 } \\
\text { 营地震保险产品, 政 } \\
\text { 府在保险市场出现供 } \\
\text { 给不充分时, 通过提 } \\
\text { 供临时性的剩余保险 } \\
\text { 市场供给以解决地震 } \\
\text { 保险供给不足的问 } \\
\text { 题。 }\end{array}$ & 日本 \\
\hline $\begin{array}{l}\text { 市场 } \\
\text { 主导 } \\
\text { 一政 } \\
\text { 府辅 } \\
\text { 助型 }\end{array}$ & $\begin{array}{l}\text { 政府不介 } \\
\text { 入地震保 } \\
\text { 险市场, } \\
\text { 通过建立 } \\
\text { 地震保障 } \\
\text { 基金等方 } \\
\text { 式间接推 } \\
\text { 动地震保 } \\
\text { 险市场发 } \\
\text { 展。 }\end{array}$ & $\begin{array}{l}\text { 市场发挥作用大, 民 } \\
\text { 众参与自愿、自由度 } \\
\text { 高, 政府掌控度低, } \\
\text { 但在应对地震灾害较 } \\
\text { 大突发风险时, 容易 } \\
\text { 产生保险公司破产等 } \\
\text { 市场经济问题。 }\end{array}$ & $\begin{array}{l}\text { 美国 } \\
\text { 加州 } \\
\text { 地区 }\end{array}$ \\
\hline
\end{tabular}

\section{1 新西兰地震保险}

新西兰的地震保险制度建立的时间最早, 也是 目前世界上运作最成功的灾害保险制度之一。新西 兰位于环太平洋火山地震带上, 平均每年发生地震 将近 3000 次。1 942 年在其首都惠林顿地区发生了 一次 7.2 级地震, 造成大量房屋建筑破坏, 由于缺 乏资金, 受损的房屋多年没有得到修复。为了吸取 这一教训, 新西兰 1945 年成立了地震和战争破坏 委员会, 颁布《地震与战争损害法案》, 其目的是
帮助新西兰民众在遭受地震灾害后重返和重建自 己的家园。新西兰又分别在 1988 年和 1993 年进一 步完善了法案, 地震和战争破坏委员会也直接更名 为地震委员会, 专门管理地震保险业务。通过版布 法案的形式, 新西兰地震保险以法律形式建立多渠 道巨灾风险分散体系, 地震风险的应对体系包括政 府机构 (地震委员会) 、保险公司 (商业机构) 和 保险协会（社会组织）。

目前新西兰地震委员会已积累约 56 亿新元的 巨灾风险基金。巨灾风险基金的主要来源是强制征 收的保险费以及基金在市场投资中获得的收益。居 民向保险公司购买房屋或房内财产保险时, 会被强 制征收地震巨灾保险保费。也即在购买房屋保险时, 强制同时购买住宅地震险保费为 50 新元 (费率 $0.05 \%$ ）、个人财产地震险保费为 10 新元。保险公 司代为征收后再交给地震委员会。一旦地震灾害发 生, 地震委员会负责法定保险的损失赔偿 (住宅最 高责任限额为 10 万新元, 个人财产最高责任限额 为 2 万新元); 保险公司依据保险合同负责超出法 定保险责任部分的损失赔偿; 而保险协会则负责启 动应急计划。当巨灾损失金额超过地震委员会支付 能力时, 政府将发挥托底作用, 由政府负担剩余理 赔支付。除建立巨灾风险基金外, 新西兰地震委员 会还利用国际再保险市场进行分保, 从而分散风险。 [3]

\section{2 日本地震保险}

日本位于环太平洋地震带, 地震灾害频发。 1964 年的新潟 7.5 级地震推动日本地震保险制度 建设取得实质性进展。这次地震后, 日本政府设立 “地震保险专门委员会”, 全方位论证地震保险制 度建设相关问题。1966 年日本推出《地震保险法》 和《地震再保险特别会计法》, 标志着日本地震保 险制度正式建立。同年 6 月 1 日地震保险开始在日 本全面推广。日本的地震保险分为住宅和商业两种。 日本政府认为住宅是人民的生活重心, 一旦遭到损 毁将形成社会问题, 因此日本政府主要参与住宅地 震保险, 而商业地震保险通过商业保险市场提供。

不同于新西兰, 日本地震保险制度采取自动附 加半强制性方式。即不允许仅订立地震保险合同, 而是在订立住宅或店铺综合保险、普通火灾保险、 住宅火灾保险合同时附加订立地震保险合同。日本 地震保险费率是在标准费率基础上, 根据区域地震 活动的等级、建筑年限、建筑类型和抗震等级等因 素进行调整。日本地震再保险株式会社 (JER) 和相 
关研究机构对日本的地震发生规律及受灾特征进 行分析研究, 在对地震危险度进行评价的基础上, 根据地震危险度大小将日本区域单位划分为 4 个 等级和 8 个费率档次, 基本费率从 $0.05 \%$ $0.313 \%$ 不等。日本地震保险最初实施时, 只对完全损毁的 住宅建筑进行赔偿, 1980 年以后进行了逐步修订, 目前是分为三个层次: 如果是全部损坏, 按 $100 \%$ 赔付; 一半损坏赔付 $50 \%$; 一部分损坏仅赔付 $5 \%$ 。 在全国对住宅损害程度的判断有统一标准。但是, 即使是全部损坏, 赔付额也不足以让灾民用来重建 住宅, 只能用作临时租房和重建房屋的补充资金, 因此日本地震保险只是确保投保人在震灾之后的 生活安定。无论如何, 2011 年东日本大地震后, 日本民众对加入地震保险的必要性有了新的认识, 未加入地震保险者中有 $60 \%$ 的人有意加入。 ${ }^{[4]}$

\section{3 美国加州地震保险}

美国加州地区也是世界上地震灾害最严重的 地区之一。在 1994 年洛杉矶 6.6 级地震之前, 美 国的地震保险均是由商业保险公司按照市场化运 作。1994 年的地震导致了美国有史以来最大的人 员伤亡和经济损失, 保险公司受理了超过 30 万件 索赔, 支付的赔款远超过过去 30 年收取保费的总 和, 巨额赔付使得商业保险公司的地震保险经营陷 入困境, 十几家保险公司因此破产。许多家庭由于 得不到地震保险保障, 而无法申请购房和重建资金 的银行贷款, 严重滞延了加州地震之后的经济复苏。 为此, 1996 年加州立法决定成立加州地震局 (CEA)。

不同于新西兰的地震委员会日本地震保险专 门委员会, 加州地震局并不是政府机构, 而是私有 公办机构。该机构由保险公司自由参加和出资、由 公共机构管理。与加州地震局结盟的保险公司在收 取地震保险费用后, 除去手续费外, 全额划转至加 州地震局。目前加州地震局的资本金约为 25 亿美 元、偿付能力超过 80 亿美元。在地震发生后, 保 险公司负责承担具体赔付工作, 并向加州地震局全 额报账。加州地震局 (CEA) 与地震风险建模公司 $\mathrm{EQE}$ 合作, 根据地震风险区划的结果, 将加州划分 成为了 19 个费率区, 费率从 $0.11 \%-0.525 \%$ 不等。 在加州, 居民购买住宅地震保险, 既可以选择通过 地震局成员公司购买, 也可以选择通过非成员公司 购买。住宅地震保险的保险金额等于房屋保单的保 险金额, 保费根据居住区域、建筑年限、建筑类型、 楼层数量、投保金额等因素确定。
通过比较新西兰、日本和美国等三个国家的地 震保险制度、模式特点、发展历程、法律法规, 地 震保险制度具有一些共同特征: 第一, 与其他保险 比较, 地震保险的政府参与度高, 政策性和强制性 强。地震保险是巨灾保险。由于地震造成损失的巨 大性及保险经营 “大数法则” 的难以运用, 缺乏政 府的推动和支持, 仅以商业保险公司为主的地震保 险机制是难以建立。1994 年的美国洛杉矶地震造 成十多家保险公司破产就是例证。因此目前世界上 大多国家的地震保险是政府官方直接管理或者由 其授权的机构进行管理、运作，并提供政策支持和 资金基本保障, 运作上一般采用商业化市场模式。 ${ }^{[5]}$ 第二, 灾难性地震事件是推动地震保险事业发展 的重要力量; 第三, 地震保险市场风险性高。保险 公司面临灾赔高风险特征, 所以多个国家建立了分 担机制。综合国外地震保险经验看, 值得重点借鉴 的是政府如何根据本国国情更好的提供政策的顶 层设计保障, 从而建立科学合理的多层次分担和补 偿机制。

图 1 对比了近些年来国内外 7 次大地震的保险 赔付情况 ${ }^{[6]}$ 。可以明显看出, 采取政府为主导的新 西兰地震保险在震后减轻地震灾害损失方面, 发挥 的作用最大, 赔付率高达 $80 \%$ 。日本的地震保险赔 付率从 1995 年阪神地震的 4\%增长到了 2013 年 311 地震的 $16.7 \%$ 。可见通过制度的不断完善, 参加地 震保险的人数也会越来越多, 地震保险发挥的作用 也就会越来越大。

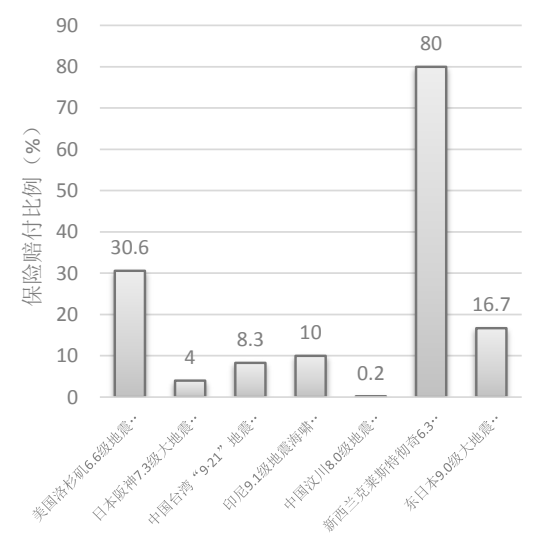

图 1 国内外 7 次大地震的保险赔付情况 


\section{3. 我国地震造成的经济损失}

我国地处环太平洋地震带和欧亚大陆地震带 之间, 地震活动具有强度大、分布广、频率高、震 源浅、地区差异显著等特点。我国西部地区地震活 动频度高、强度大, 经济相对落后、人口密度低; 东部地区地震活动频度相对较低, 虽然经济较发达, 但是地震防范意识淡薄 ${ }^{[7]}$ 。

本文统计了我国大陆地区 2006 年-2017 年发 生的 112 次地震经济损失评估数据, 震级范围: 4.0 级 -8.0 级; 地震造成的直接经济损失总体是随着 震级的增加而加大, 如图 2 所示。本文暂不考虑通 货膨胀对地震损失的影响。

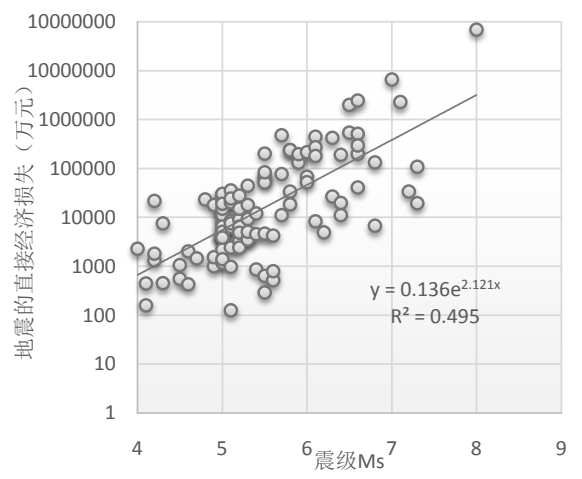

图 2. 我国 2006 年-2017 年地震造成的直接经济损失

在相同震级情况下, 不同地区地震造成的直接 经济损失差异很大, 例如, 我国发生的 5 级破坏性 地震造成的经济损失进行统计, 可以看出, 从 1185.05 万- 30250 万元, 相差 30 倍。另外, 同一 地区也容易发生不同震级的地震, 如新疆于田县 2008 年发生了 7.3 级地震, 造成经济损失达 19479.9 万元, 2011 年 10 月 16 日, 发生了 5.0 级地震, 造成直接经济损失 290 余万元, 2017 年, 又发生了 6.6 级地震, 直接经济损失近 1.5 亿元。 因此, 我国地震灾害的复杂性导致地震保险赔付工 作复杂, 地震风险造成地震保险实施难度更大。

\section{4. 我国地震保险的现状及问题分析}

我国地震灾害风险高, 地震造成的灾害损失呈 现多样性。全国各个地区自然和人文环境迥异、建 筑特点也不同, 震后损失具有很大差别; 即使是同 一区域的同类建筑, 由于建设时期不同, 提出的抗
震设防要求自然不同, 因而具有的抗震设防能力也 不同。因此, 我国地震保险面临的形势复杂多样。 我国地震保险发展经历了多个发展阶段。从建 国初期, 地震保险首次作为火险附加险出现, 中间 经历过两次全国范围内停办现象。第一次停办是 1958 年, 当时所有的保险业务在全国范围内停办, 地震保险随之消失。1980 年, 我国重新回复开展 保险业务后, 开办地震保险, 虽然范围较小。在 1988 年澜沧-耿马地震之前, 云南保险分公司对 1985 年禄劝 6.3 级地震 (赔付 57 万元、地震损失 2000 万元）; 1987 年施甸 5.5 级地震（赔付 50 万元、地震损失 600 万元）以及 1988 年宁蒗 5.5 级地震（赔付 258 万元、地震损失 3600 万元）进 行了理赔工作。 ${ }^{[8]}$ 这些地震因为赔款数目不大, 但 是 1988 年澜沧-耿马地震 (双主震, M7.6、7.2), 作为我国保险历史上遇到的第一次 7 级以上大地 震, 再次引起了人们对地震这种突发性巨灾所造成 的损失是否赔付得起的疑问。以该次地震重灾区的 临沧地区保险中支公司为例, 该公司 1981-1988 年积累的保费为 1180 万元, 而本次地震赔款就达 到 1400 万元 ${ }^{[9]}$ 。如果按照美国 1994 年的洛杉矶地 震经验, 该保险公司也该破产。由于对地震保险风 险过大, 我国将地震保险列为 “财产保险的除外责 任”, 事实上第二次中止了地震保险。

近十年来, 特别是汶川地震之后我国又开始重 视发展地震保险, 地震保险试点地区不断扩展, 国 家不断出台有关政策, 并逐步确立了我国地震保险 发展方案与思路。2014 年 8 月 13 日, 国务院发布 保险业“新国十条”, 提出完善保险经济补偿机制, 提高灾害救助参与度, 将保险纳入灾害事故防范救 助体系, 建立巨灾保险制度。2016 年 5 月中国保 监会、财政部出台了《建立城乡居民住宅地震巨灾 保险制度实施方案》（保监发〔2016〕39 号）。 为保证地震巨灾保险顺利实施, 由中国保险行业协 会牵头组织, 多家保险公司共同成立了中国城乡居 民住宅地震巨灾保险共同体。

与国外发达国家地震保险发展水平相比, 目前 我国地震保险发展水平偏低。我国地震灾害损失补 偿中, 保险赔付金额占损失金额比例小, 远远低于 国际 30\%的标准 ${ }^{[10]}$ 。因此, 我国保险在地震灾害损 失补偿发挥的作用很小。

目前, 制约我国地震保险行业快速发展主要存 在以下问题:

(1) 我国地震保险发展的地区与地震风险形 成倒挂现象。我国目前地震保险试点及推行区域主 
要集中在经济发达的东部地区, 但是东部地震风险 较低, 地震保险能够发挥的作用较少, 影响力也相 对要小。对于西部地震风险相对较高, 需求量大, 但是西部地区经济不发达, 地震保险推行难度大。

(2) 长期以来, 我国推行巨灾救助举国体制, 地震保险的覆盖面相对很低, 民众对于发生地震灾 害后，依赖国家救助的思想非常严重。民众整体对 于地震保险参保意识仍需不断加强。

（3）相比美国等发达国家地震保险商业化模 式, 我国地震保险市场不成熟, 商业化水平低。由 于基础薄弱, 商业保险公司对地震保险的承保能力 和经验方面相对较差。同时, 我国的地震风险高, 强烈地震非常容易造成巨大经济损失, 一次特大地 震甚至会导致市场化运作的保险公司直接倒闭。根 据正式发布的中国保监会数据, 2008 年发生的汶 川 8.0 级地震造成直接经济损失 8523 亿元, 保险 赔付 16.6 亿元, 仅占总损失比例为 $0.02 \%$ 。据统 计, 财产保险行业资产 2007 年末总额共计 3880.51 亿元, 若进行财产赔付, 汶川地震就将造成保险公 司严重透支。 ${ }^{[11]}$ 此外, 无论是与国外同行相比, 还 是与我国银行业相比, 我国保险业在风险控制方面 还有许多不足 ${ }^{[10]}$ 。

（4）地震保险制度和管理体制不完善，尤 其是费率制定难度较大。通过分析近些年内发生 的 112 次地震, 地震灾害风险造成的经济损失出 现极值可能性大。例如, 2008 年我国发生的汶川 地震造成的直接经济损失达 8523 亿元, 这种巨灾 问题使保险公司难以确定合适的费率, 从而大大影 响保险公司对于稳点经营的客观要求 ${ }^{[12]}$ 。另外, 由 于我国接壤国家也处在地震活动带, 尤其在国外发 生的地震, 地震资料相对较少, 对于我国国内边境 地区地震保险的费率确定工作也增加了难度。同时, 地震发生的震级大小、破坏程度具有时空不确定性, 保险公司确定各地不同的费率水平有一定的困难, 从技术层面上规避风险有困难。

鉴于以上论述, 地震造成我国严重的经济损失, 地震保险作为一种资源储备和经济补偿手段, 是实 现社会救助、减轻政府负担、提高抗震救灾能力、 稳定社会的有效途径 ${ }^{[14]}$ 。在我国现行灾害事故防范 救助体系中通过加快推进地震保险立法, 强制完善 地震保险制度和管理体制的必要性和可行性。

\section{5. 建议及对策}

在开展我国地震保险工作中, 借鉴国际经验同 时, 也不能照搬国外已有地震巨灾风险模式, 应建
立符合我国国情的地震保险制度。为不断完善我国 地震保险制度, 提出以下具体建议和对策:

（1）针对经济发展的不平衡, 建议采用政府 主导, 市场辅助运作的模式。特别是西部地区, 政 府为地震保险保底, 提供足够的资金保障, 加大政 策制度支持力度。地震保险不以盈利为目的, 但应 通过市场化手段, 尽力减轻国家财政负担, 保持社 会稳定。 ${ }^{[15]}$

（2）加强地震保险相关的地震科学基础研究 工作。在充分研究我国地震风险特点基础上, 对可 能发生地震的地点进行详细评估, 是研究地震保险 的科学基础。同时, 以中国地震动参数区划图为科 学基础依据, 综合研究建筑易损性的时空分布特性, 建立符合我国国情的地震保险易损性风险模型。最 后, 加强基于地震保险的费率机制定制等具体问题 研究。综合考虑政府部门、保险公司、投保人的意 见, 做到费率厘定既有政策稳定性, 也具有时空分 布的动态化特征。

（3）提升民众地震保险意识, 加强地震保险 宣传。建议借助地震事件, 加强地震保险宣传推广。 例如, 昌宁发生 5.1 级地震后, 云南通过电视、网 络等多种媒体方式进行地震保险宣传, 让民众了解 地震保险 ${ }^{[16]}$ 。通过多种途径社会宣传, 提高民众意 识, 让民众真正接纳地震保险, 做到保险理念深入 民心。

(4) 建议发挥我国社会主义制度及文化传统 上的优势, 采用 “政府主导、多元参与、全社会动 员” 的模式, 认真总结汶川地震抗震救灾和恢复重 建的经验, 构建多级多层分担机制, 以应对地震巨 灾风险。

总之, 随着我国经济实力的不断增强, 民众财 产意识的逐渐提升, 地震保险的制度化、市场化、 科学化水平不断提升, 地震保险将会进入飞速发展 快行道, 建立符合我国国情的地震保险制度会更好 的保障居民财产, 提升我国地震灾害恢复能力。

\section{Acknowledgements}

This study was supported by the Special Fund of the Institute of Geophysics, China Earthquake A dministration (DQJB17C006, DQJB18B18).

\section{致谢}

本项研究受到中央级公益性科研院所基本业务 专项（DQJB17C006, DQJB18B18）的资助。 


\section{参考文献}

[1] 隋神宁,地震保险法律制度基本问题,白城师 范学院学报,24(1):41, 2010.

[2] 王银成,国际巨灾保险制度比较研究,中国金 融出版社, 北京, 2013 .

[3] 杜婧,从国际经验看我国地震巨灾保险基金的 建立, 保险职业学院学报 (双月刊), 28(4):39,2014.

[4] 赵苑达, 论我国地震保险制度的建设, 保险研 究, 10, 2003.

[5] 酆瑞, 从雅安地震看中国地震保险市场问题及 对策,经济视野,2014.

[6] 袁力, 王和, 地震保险制度研究, 中国经济出版 社,北京,2013.

[7] 杨格格, 杨艳昭, 游珍等, 中国陆域地震灾 害的时空分布格局, 地球科学进展, 26(5): 548-555, 2011.

[8] 李永强, 李年生, 城乡居民住宅地震巨灾保险 风险模型,云南科技出版社,昆明,2017.

[9] 林蓉辉, 从澜沧-耿马地震看地震保险业的发
展,国际地震动态，（8）:8-11, 1989.

[10] 杨天一, 建立地震巨灾保险制度的实践与路 径思考, 四川文化产业职业学院 (四川省函 授学院）学报，(1):137-140，2017.

[11] 范红梅, 云南房屋地震保险经营模式探究, 上海保险，45-48，2016.

[12] 郑山锁, 相泽辉, 郑捷等, 我国建筑物地震 保险制度及保险费率厘定研究, 灾害学, 31(3):1-7, 2016.

[13] Guo Z H. Economic fluctuations and insurance industry crisis: the history, status quo and the future. Journal of Risk Analysis and Crisis Response, 6 (1): 38-46, 2016.

[14] 马玉宏, 赵桂峰, 谢礼立等, 基于地震危险性特 征分区的建筑物地震保险费率,四川建筑科学 研究,35 (6) :197-200, 2009.

[15] 车唐红, 宋珊珊, 杨振刚, 从日本福岛地震看中 国地震保险,知识经济,(12):39, 2011.

[16] 谢巍,陈勤, 张俊伟, 云南地震保险制度建设研 究,防灾博览,(1): 16-21, 2017. 